\title{
ISOLASI PIGMEN KAROTENOID PADA MIKROALGA Nannochloropsis sp. DENGAN MENGGUNAKAN BEDA PELARUT
}

\author{
[Isolation of Carotenoid Pigments in Microalga Nannochloropsis sp. with Different \\ Solvents]
}

\section{Miranti Bawias $^{1^{\star}}$, Kurniati Kemer ${ }^{1}$, Desy M.H. Mantiri ${ }^{1}$, Deislie R. Kumampung ${ }^{1}$, Darus S. J. Paransa ${ }^{1}$, Rose Mantiri ${ }^{2}$}

1. Program Studi Ilmu Kelautan, Fakultas Perikanan dan Ilmu Kelautan, Universitas Sam Ratulangi, Manado.

2. Program Studi Manajemen Sumberdaya Perairan, Fakultas Perikanan dan Ilmu Kelautan, Universitas Sam Ratulangi, Manado.

*e-mail : mirantibawias@gmail.com

This study aims to isolate the pigment types of Nannochloropsis sp microalgae. and know the solvent composition which can separate the pigment optimally. The method used started from microalga culture Nannochloropsis sp. until exponential phase. Extraction was performed by addition of acetone and petroleum ether, then total extract obtained, separated by Thin Layer Chromatography with Petroleum Ether (PE) developer: Acetone (80:20), PE: Methanol (95: 5) and Benzene: DE: Methanol ( 17: 2: 1). The separation result is absorbed by UV-VIS spectrophotometer. The results obtained in all separation processes, yellow $\beta$-carotene pigments always appear with $\mathrm{Rf} 1.00$. Other identifiable pigments are the type violaxantin and the astacen type. PE solvent: Methanol (95: 5) is able to separate the total extract of the pigment more than the other solvent.

Keywords: Nannochloropsis sp., Pigments, TLC, $\beta$ - karoten

Penelitian ini bertujuan untuk mengisolasi jenis-jenis pigmen dari mikroalga Nannochloropsis sp. dan mengetahui komposisi pelarut yang dapat memisahkan pigmen secara maksimal. Metode yang digunakan dimulai dari kultur mikroalga Nannochloropsis sp. sampai tahap eksponensial. Ekstraksi dilakukan dengan penambahan aseton dan petroleum eter, selanjutnya ektrak total yang diperoleh, dipisahkan melalui Kromatografi Lapis Tipis dengan pengembang Petroleum Eter (PE):Aseton (80:20), PE:Methanol (95:5) dan Benzena:DE:Methanol (17:2:1). Hasil pemisahan diserap melalui spektrofotometer UV-VIS. Hasil yang peroleh pada semua proses pemisahan, pigmen $\beta$ - karoten berwarna kuning selalu muncul dengan $\mathrm{Rf} 1,00$. Pigmen lainnya yang dapat diidentifikasi adalah tipeviolaxantin dan tipe astacen. Pelarut PE:Methanol (95:5) mampu memisahkan ekstrak total pigmen lebih banyak dibandingkan dengan pelarut yang lain.

Kata Kunci : Nannochloropsis sp., Pigmen, KLT, $\beta$ - karoten

\section{PENDAHULUAN}

Wilayah Indonesia sebagian besar merupakan laut dan memiliki kekayaan yang beranekaragam. Saat ini, penggalian potensi biota laut terutama mikroalga untuk meningkatkan ketahanan pangan masih sangat minim. Dengan wilayah perairan yang sangat luas ini, Indonesia sebenarnya memiliki potensi yang sangat besar dalam menemukan spesies mikroalga yang cocok untuk dikembangkan sebagai sumber farmasitika dan nutrisi (Anggreni, 2015).

Saat ini mikroalga tidak saja diperuntukkan bagi dunia perikanan (sebagai pakan alami rotifer dan larva ikan) namun sangat potensial untuk dikembangkan sebagai 
suplemen makanan, farmasi, dan kosmetik. Keunggulan dari mikroalga adalah tidak tergantung pada musim, waktu pertumbuhan mikroalga selama 2 minggu sehingga, waktu panen tidak lama, produksi dapat dilakukan secara terus menerus, tidak berdampak buruk bagi lingkungan, produksinya dapat dilakukan sesuai dengan kebutuhan, serta aman bagi kesehatan. Mikroalga mengandung berbagai macam komponen yang sangat bermanfaat khususnya untuk nutrisi dalam bahan pangan, seperti lipid, karbohidrat, protein dan asamasam nukleat (Brown et al, 1993; Sankar and Ramasubramanian, 2012).

Nannochloropsis

sp.

merupakan contoh mikroalga yang berpotensi untuk dikembangkan terutama sebagai sumber karotenoid. Kandungan karotenoid dari 15 mikroalga mencapai 65\% dari bobot biomassa keringnya (Hossain et al., 2008; Vonshak 1996), berbagai jenis pigmen yang dihasilkan dari mikroalga dapat dimanfaatkan sebagai sumber antioksidan dalam bahan pangan. Menurut Kawaroe et al. (2010) pola pertumbuhan mikroalga pada sistem kultivasi terbagi menjadi 5 tahapan yaitu, fase adaptasi (lag phase), fase eksponensial (log phase), fase penurunan pertumbuhan (declining growth), fase stasioner, fase kematian (death phase).

Pigmen karotenoid terdiri dari karoten dan xantofil. Karoten merupakan prekursor vitamin A yang berguna bagi tubuh manusia yang dimetabolisme dari $\beta$-karoten dengan perantaraan enzim. Didalam tubuh manusia prekursor vitamin A akan dimetabolisme menjadi dua molekul vitamin $A$ yang sangat berguna bagi aktivitas fisiologi terutama organ mata (Gross, 1991; Mantiri \& Kepel, 1999, Merdekawati \& Susanto. 2009). Sedangkan menurut Mutschler (1991), vitamin E merupakan senyawa hasil hidrolisis dari pigmen karotenoid.

Metode yang umum digunakan dalam menentukan jenis pigmen karatenoid yakni metode Kromatografi Lapis Tipis (KLT). Metode ini dikenal mudah, sederhana dan hanya membutuhkan waktu yang relatif singkat dengan hasil yang cukup akurat (Adnan, 1997). Menurut Stahl (1985) bahwa analisis Kromatografi Lapis Tipis (KLT) mempunyai keunggulan lebih dibandingkan dengan Kromatografi lainnya karena KLT merupakan satu-satunya teknik kromatografi yang menganalisis berbagai campuran komponen secara serempak melalui polaritas. Tahap pemisahan pigmen menggunakan metode KLT adalah baik untuk menentukan pemisahan jenis pigmen semi polar menggunakan larutan organik Pertroleum Eter (PE) dan Aseton dengan perbandingan 80:20. Pemisahan pigmen yang berada pada area non polar adalah Petroleum Eter (PE) dan Metanol dengan perbandingan 95:5. Pemisahan pigmen di area polar adalah dengan larutan Benzena, Dietil Eter, dan Methanol dengan perbandingan 17:2:1 (Mantiri et al. 1995; Mantiri, 1997).

\section{METODE PENELITIAN}

\section{Kultur Mikroalga}

Mikroalga Nannochloropsis sp. yang digunakan berasal dari Balai Besar Perikanan dan Budidaya Laut di Lampung. Air laut 
yang digunakan sebagai medium mikroalga disaring dan disterilisasi dengan autoclave. Kemudian air laut yang sudah disterilkan, dimasukkan dalam wadah kultur, ditambahkan nutrien berupa larutan Conway, diaduk hingga merata (Vonshak, 1988). Nannochloropsis sp. selanjutnya dimasukan ke dalam wadah tersebut dan dikultur pada suhu ruang $25^{\circ} \mathrm{C}$, serta penerangan lampu tabung 20 watt. Kepadatan sel alga dihitung dengan haemocytometer di bawah mikroskop (Isnansetyo \& Kurniastuty, 1995).

\section{Ekstraksi Pigmen}

Ekstraksi pigmen dilakukan dalam ruangan dingin tanpa cahaya dengan mengambil alga Nannochloropsis sp. yang telah disentrifus pada kecepatan 3000 rpm selama 10 menit. Sampel diaduk dengan strirer dalam larutan aseton p.a. sebanyak $10 \mathrm{ml}$. Sampel yang berwarna hijau tersebut dimasukan dalam labu pemisah selanjutnya ditambahkan larutan petroleum eter, dan aquades, diaduk secara perlahan lalu diamkan sampai terlihat 2 lapisan (Harbone, 1987 ; Mantiri \& Tulalo, 2001). Lapisan atas adalah lapisan pigmen. Pada tahap ini telah didapat pigmen total.

\section{Pemisahan Pigmen dengan KLT Menggunakan Beberapa Larutan Pengembang}

Lapisan atas, hasil ekstraksi dianalisis dengan spektrofotometer untuk memperoleh kurva pigmen total dan nilai kepadatan optik. (Britton et al., 1995).

Proses pemisahan pigmen dengan KLT. Larutan pengembang yang digunakan adalah petroleum eter dan aseton dengan perbandingan 80:20, petroleum eter dan methanol dengan perbandingan 95:5 serta benzene, dietil eter dan methanol dengan perbandingan 17:2:1 (Mantiri, 1997). Penentuan nilai $\mathrm{Rf}$ dilakukan dengan membagi jarak yang ditempuh oleh senyawa dari titik awal dengan jarak yang ditempuh pelarut dari titik asal (Sastrohamidjojo, 1991, Matsjeh, 1999).

\section{Analisis Konsentrasi Pigmen}

Analisis kandungan pigmen
dalam larutan PE dilakukan
dengan menggunakan alat spektrofotometer. Pembacaan absorbansi dilakukan pada panjang gelombang 380-550 $\mathrm{nm}$. Menghitung konsentrasi pigmen karotenoid pada alga dalam PE menggunakan alat spektrofotometer, mengetahuinya dengan digunakan rumus (Britton et al., 1995).

\section{HASIL DAN PEMBAHASAN}

Mikroalga Nannochloropsis sp. merupakan mikroalga yang memilki berwarna hijau dan tidak berflagela. Pertumbuhan mikroalga Nannochloropsis sp. dalam kultur dapat ditandai dengan bertambah besarnya ukuran sel atau bertambah banyaknya jumlah sel yang secara langsung akan berpengaruh terhadap kepadatan mikroalga (Chretiennot-Dinnet, 1990 - Bentuk sel mikroalga dan pertumbuhan Nannochloropsis sp dapat dilihat pada Gambar 1.

Pertumbuhan mikroalga Nannochloropsis sp. dihentikkan pada hari ke-5 yaitu pada fase eksponensial dengan jumlah 
kepadatan sel rata-rata 93 sel. Fase eksponensial tergantung pada umur sel, kepadatan awal dan faktorfaktor penunjang. Selanjutnya dilakukan ekstraksi pigmen. Pada kultur fase penurunan, pertumbuhan (declining growth) masih dilanjutkan sampai fase kematian.

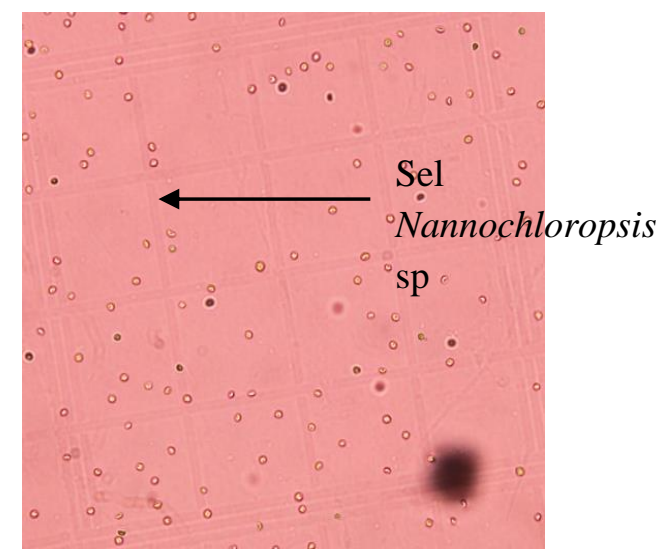

Gambar 1. Sel Nannochloropsis sp. (pembesaran $60 \mathrm{x}$ ).

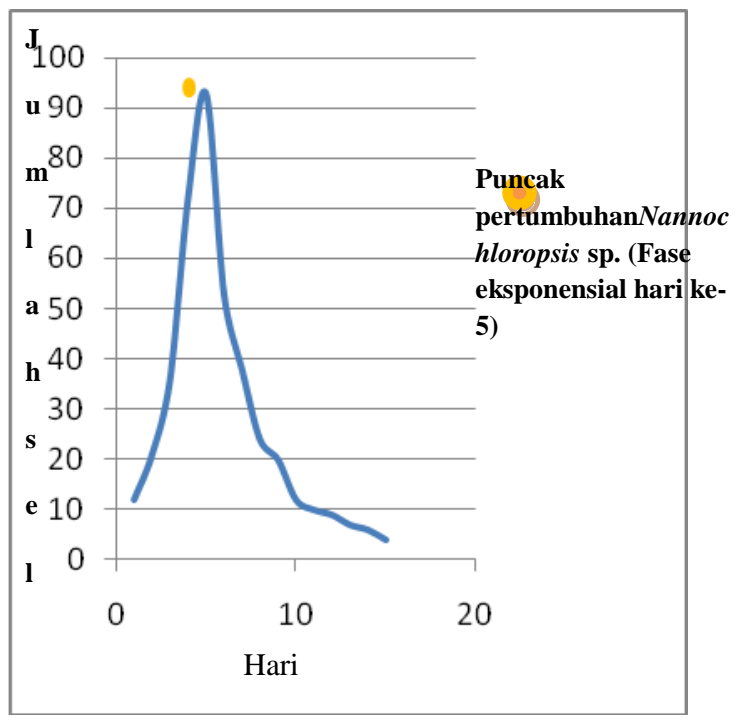

Gambar 2. Kurva pertumbuhan Nannchloropsis sp.

\section{Analisis Pigmen Total Nannochloropsis sp.}

Hasil ekstraksi awal sampel mikroalga Nannochloropsis sp. memiliki warna kehijauan karena ekstrak tersebut masih tercampur dengan klorofil. Namun yang menjadi tujuan penelitian pada Nannochloropsis sp. adalah pigmen karotenoid dengan mempunyai batasan serapan panjang gelombang 380-550 nm. Hasil serapan dengan spektrofotometer UV-VIS ekstrak Nannochloropsis sp. ini membentuk tiga puncak gelombang yaitu pada panjang gelombang 410, 430, $460 \mathrm{~nm}$ (Gambar 3). Spektogram ini memperlihatkan mayoritas pigmen yang dikandung adalah jenis karoten, pigmen yang umumnya terdapat pada mikroalga hijau (Mantiri \& Tulalo, 2001)

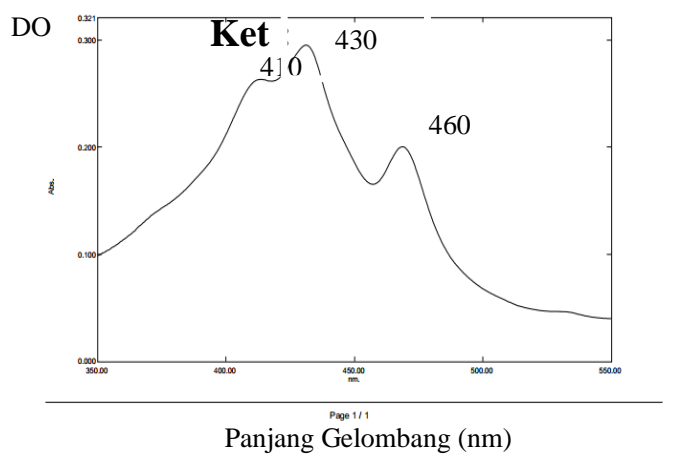

Gambar 3. Spektogram ekstrak pigmen total Nannochloropsis sp. dalam PE. 
Analisis Pigmen dengan Beberapa Larutan Pengembang

Hasil pemisahan ekstrak total pigmen dengan kromatografi lapis tipis, menggunakan beberapa larutan pengembang dapat dilihat pada Tabel 1- 3.

Hasil analisis ekstrak pigmen total yang dipisahkan berdasarkan polaritas dengan KLT menggunakan tiga larutan pengembang yang berbeda adalah untuk melihat

Tabel 1. Hasil pemisahan KLT dan serapan pigmen dengan spektrofotometer ekstrak pigmen total, larutan pengembang Petroleum Eter : Aseton (80:20).

\begin{tabular}{cccc}
\hline Fraksi & Rf & $\begin{array}{c}\text { Panjang } \\
\text { Gelombang } \\
(\mathbf{n m})\end{array}$ & $\begin{array}{c}\text { Jenis } \\
\text { Pigmen }\end{array}$ \\
\hline 1 & 1.00 & $\begin{array}{c}425,450, \\
477\end{array}$ & $\beta$ - karoten \\
\hline 2 & 0.78 & $\begin{array}{c}412,430, \\
467\end{array}$ & $\begin{array}{c}\text { Tipe } \\
\text { violaxanthin }\end{array}$ \\
\hline 3 & 0.70 & 478,514 & $\begin{array}{c}\text { Tidak } \\
\text { teridentifikasi }\end{array}$ \\
\hline
\end{tabular}

Tabel 2. Hasil pemisahan KLT dan serapan pigmen dengan spektrofotometer ekstrak pigmen total, larutan pengembang Petroleum Eter : Methanol (95:5).

\begin{tabular}{cccc}
\hline Fraksi & RF & $\begin{array}{c}\text { Panjang } \\
\text { gelombang } \\
(\mathrm{nm})\end{array}$ & $\begin{array}{c}\text { Jenis } \\
\text { pigmen }\end{array}$ \\
\hline 1 & 1.00 & $\begin{array}{c}425,450, \\
478\end{array}$ & $\beta$-karoten \\
\hline 2 & 0.32 & 433,473 & $\begin{array}{c}\text { Tipe } \\
\text { Astacene }\end{array}$ \\
\hline 3 & 0.14 & 414,428 & $\begin{array}{c}\text { Tidak } \\
\text { teridentifikasi }\end{array}$ \\
\hline 4 & 0.08 & 410,428 & $\begin{array}{c}\text { Tidak } \\
\text { teridentifikasi }\end{array}$ \\
\hline
\end{tabular}

Tabel 3. Hasil pemisahan KLT dan serapan pigmen dengan spektrofotometer ekstrak pigmen total, larutan pengembang Benzena : Dietil eter : Methanol (17:2:10).

\begin{tabular}{cccc}
\hline Fraksi & RF & $\begin{array}{c}\text { Panjang } \\
\text { gelombang } \\
(\mathrm{nm})\end{array}$ & Jenis pigmen \\
\hline 1 & 1.00 & $\begin{array}{c}425,450, \\
477\end{array}$ & $\beta$-karoten \\
\hline 2 & 0.87 & 415 & $\begin{array}{c}\text { Tidak } \\
\text { teridentifikasi }\end{array}$ \\
\hline 3 & 0.75 & 414 & $\begin{array}{c}\text { Tidak } \\
\text { teridentifikasi }\end{array}$ \\
\hline
\end{tabular}

pemisahan yang paling baik. Pemisahan dengan larutan pengembang Petroleum Eter : Aseton (80:20) adalah baik untuk memisahkan pigmen di area

semipolar. Hasil isolasi menunjukan pigmen ektrak total terpisah tiga jenis pigmen (Tabel 1). Pigmen yang jelas pada spektogram adalah Rf 1,00 setelah diidentifikasi (Briton $d k k, 1995)$ yaitu pigmen $\beta$-karoten $(\beta-\beta$ karoten) dengan panjang gelombang $425 \mathrm{~nm}, 450 \mathrm{~nm}$ dan $477 \mathrm{~nm}$. Lapisan lainnya adalah pigmen tipe violaksantin.

Pemisahan pigmen dengan KLT menggunakan larutan pengembang Petroleum Eter: Methanol (95:5) memperoleh 4 (empat) lapisan (Tabel 2). Perbandingan larutan pengembang ini baik untuk memisahkan jenisjenis pigmen yang berada pada area non polar (Mantiri, 1997). Hasil isolasi memperoleh empat jenis pigmen, $\mathrm{Rf} 1,00$ adalah pigmen $\beta$ karoten dengan panjang gelombang $425 \mathrm{~nm}, 450 \mathrm{~nm}$ dan $478 \mathrm{~nm}$. Pigmen pada $\mathrm{Rf} 0,32$ adalah tipe astacen (Gambar 5). Dua lapisan 


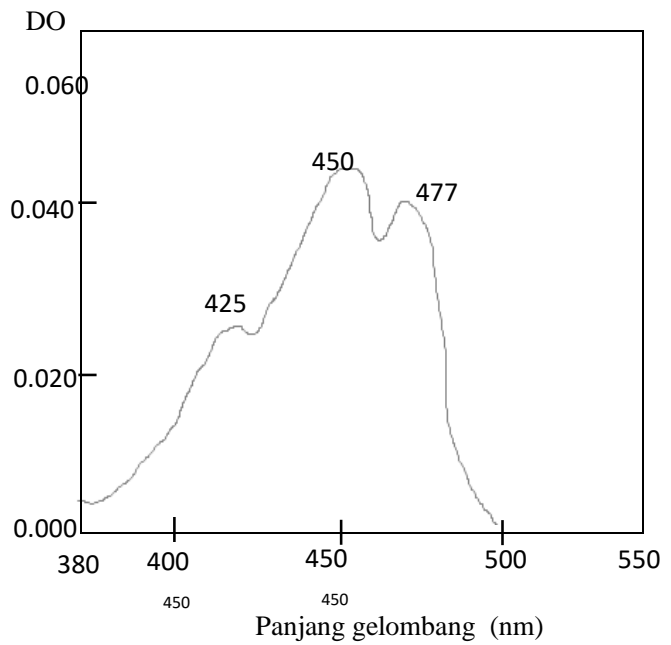

Gambar 4. Spektrogram pigmen hasil KLT fraksi 1 (PE:Aseton, 80:20) dalam PE.

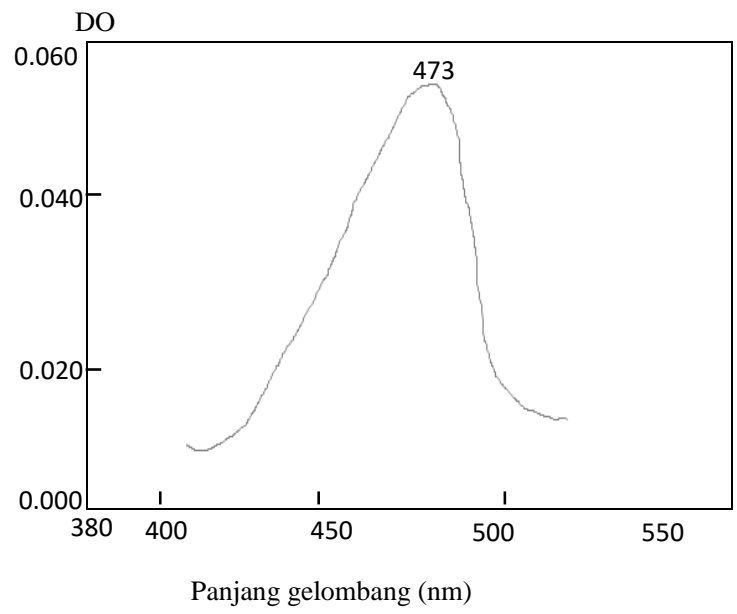

Gambar 5. Spektrogram pigmen hasil KLT fraksi 2 (PE:Methanol, 95:5) dalam PE.

yang diisolasi, tidak dapat diidentifikasi oleh karena kepadatan optik terlalu rendah.

Hasil KLT dengan larutan pengembang Benzena : Dietil eter : Methanol (17:2:10) dapat memisahkan ekstrak pigmen total menjadi 3 (tiga) lapisan.namun hanya pigmen dengan Rf 1,00 yang dapat diserap dengan baik oleh spektrofotometer dan teridentifikasi pigmen $\beta$-karoten.

Pigmen $\beta$-karoten $(\beta-\beta$ karoten) adalah pigmen yang merupakan prekursor awal dalam proses metabolisme pada organisme. Oleh karenanya sering ditemukan dalam proses pengembangan melalui KLT pada berada pada Rf 1,00 dengan warna kuning walaupun larutan pengembang berbeda-beda. Pigmen $\beta$ - karoten ditemukan juga pada mikroalga dengan $\mathrm{Rf} 1,00$ dalam penelitian Balaira, et al. (2016) dan penelitian Mantiri \& Tulalo (2001). Walaupun dalam kultur mikroalga diberi perlakuan namun pigmen $\beta$-karoten tetap muncul (Mantiri et al., 2001).

Dalam proses metabolism pada organisme pigmen $\beta$ - karoten dapat berkonyugasi dengan gugus alkohol dan atau gugus keton (Goodwin, 1988). Struktur pigmen ini dapat berubah menjadi xantofil antara lain tipe violaxantin dan tipe astacen seperti yang terdeteksi

Dari ketiga komposisi larutan pengembang yang digunakan pada alga mikroalga Nannochloropsis sp., pelarut petroleum eter : methanol (95:5) dapat memisahkan empat jenis pigmen. Untuk itu perlu dicobakan lagi beberapa jenis pelarut dengan komposisi yang berbeda untuk mengetahui jenis pigmen yang lebih banyak.

\section{KESIMPULAN}

Jenis-jenis pigmen yang diperoleh melalui pemisahan 
dengan KLT adalah $\beta$ - karoten, tipe violaksantin dan tipe astacen. Pigmen $\beta$-karoten yang paling dominan dari ketiga beda pelatutyang digunakan. Pemisahan pigmen total melalui KLT dengan larutan pengembang $\mathrm{PE}:$ Methanol (95:5) memperoleh empat jenis pigmen. Pelarut tersebut adalah yang paling baik untuk digunakan dalam pemisahan pigmen, pada mikroalga Nannochloropsis sp.

\section{DAFTAR PUSTAKA}

Anggreni, Dewi. 2015. Produksi Biomassa, Lipid dan Protein Sel Tunggal Mikroalga Nannochloropsissp Sebagai Suplemen Makanan. Laporan Tahunan Penelitian Hibah Bersaing.Universitas Udayana.

Adnan, M. 1997. Teknik Kromatografi Untuk Analisis Bahan Makanan. Penerbit Andi Yogyakarta.

Balaira, G.Y., Kemer, K., Mantiri, D.M.H. 2017. Pemisahan Pigmen pada Mikroalga Dunaliella salina yang Telah Diberi Senyawa Timbal Asetat. Jurnal Pesisir dan Laut Tropis. 1[1].

Britton, G, Jansen, S.L., Pfander, H. 1995. Carotenoids. Volume IB. Spectroscopy. Basel. Switzerland.

Brown M.R., Garland, C.D., Jeffrey, S.W., Jameson, I.D., Leroi, J.M. 1993. The Gross and Amino Acid Compositions Of
Hatch and Semi-continuous Cultures Of Isochrysis sp, (cloneT.ISO), Pavlova lutheli and Nannochloropsis oculala, J. Applied Phycology 5:285296.

Chretiennot-Dinnet, M.J. 1990. Atlas du Phytoplancton Marine. Volume 3.. Edition du Centre National de la Recherche Scientifique. Paris. p 261.

Gross, J. 1991. Pigment in Vegetables (Chlorophylls and Carotenoids). Van Norstran Reinhold. New York. 775 hal.

Goodwin, T.W. 1988. Plant Pigmen. Academic Press Inc. San Diego. p 363.

Harborne, J.B. 1987. Metode fitokimia : Penuntun Cara Modern Menganalisis Tumbuhan. ITB. Bandung.

Hossain, A.B.M., Salleh, A., Boyce, A. N., Chowdhurry, Naqiuddin, M. 2008. Biodiesel Fuel Production from Algae as Renewable Energy. American Journal of Biochemistry and Biotechnology. 4:250-254.

Isnansetyo, A, Kurniastuty. 1995. Teknik Kultur Phytoplankton dan Zooplankton. Pakan Alami untuk Pembenihan Organisme Laut. Yogyakarta: Kanisius.

Kawaroe, M., T. Partono, A. Sunuddin, D.W. Sari dan D. Augustine. 2010. Mikroalga, Potensi dan Pemanfaatannya Untuk Produksi Bio Bahan Bakar. Institut Pertanian Bogor Press. Bogor. $150 \mathrm{hlm}$. 
Mantiri, D. M. H. 1997. Nature, Localisation et Metabolisme des Carotienoides et des Complexes Carotenoid Proteiques au Cours de l'Evolution Embrionale et Larvaire du Homard Eurepeen Homarus gammarus (linne 1758). These Universite de Droit, d'Ecnomie et des Sciences d'Aix Marseille, Facultedes Sciences et Techniques de Saint Gerome.

Mantiri D.M.H dan Kepel B.J. 1999. Beberapa Peranan Pigmen Karotenoid. Jurnal Fakultas Perikanan. 1(3):139-147.

Mantiri D.M.H. dan Tulalo J. 2001. Pigmen Dari Beberapa Jenis Alga Mikro. Jurnal Fakultas Perikanan, 3(1):7-13.

Mantiri D.M.H., Inkiriwang P.A., Wowor P. 2001. Pengaruh Logam Tembaga Terhadap Pertumbuhan dan Kandungan Pigmen Dunaliella sp. Jurnal Fakultas Perikanan, 2(4):52-55.

Matsjeh, S. 1999. TLC.Thin Layer chromatography.Fakultas Matematika dan IImu Pengetahuan Alam. Uniersitas Gajah Madah. Yoyakarta.

Merdekawati, W dan A.B. Susanto. 2009. Kandungan dan Komposisi Pigmen Rumput Laut Serta Potensinya Untuk Kesehatan. Jurnal Fakultas Perikanan dan IImu Kelautan.
Mutschler E. 1991. Dinamika Obat. Edisi Ke-5. Penerbit ITB. Bandung.

Sankar, M., Ramasubramanian, V., 2012. Biomass Production Of Commercial algae Chlorella vulgaris On Different Culture Media. J. Life Science, 1:5660.

Sastrohamidjojo, H. 1991. Kromatografi. Penerbit Liberty Yogyakarta.

Stahl, E. 1985. Analisis Obat Seara Kromatografi dan Mikroskopi. Diterjemahkan Oleh Dr. K Padmawinata dan Dr. Iwang Soediro ITB Bandung.

Vonshak. 1988. Porphyridium In Macro-Algae Biotechnology. Ed. Borowitzka M.A and Borowitzka L.J. Cambridge : University Press.

Vonshak.1996. Spirulina platensis [Arthospira). Taylor \& Francis, Great Britain. 